\title{
Story reading with incidental comprehension and memory: left hemisphere dominance
}

\author{
Lectura de una historia con comprensión y memoria incidentales: dominancia del \\ hemisferio izquierdo
}

Nora Silvana VIGLIECCA ${ }^{1,2}$

\begin{abstract}
Background: There are no studies on adults with unilateral brain lesions regarding story reading with incidental/implicit comprehension and memory, in which memory is only assessed through delayed recall. There is a need for validation of cerebral laterality in this type of verbal recall, which includes spontaneous performance (free or uncued condition (UC)), and induced-through-question performance regarding the forgotten units (cued condition (CC)). Objectives: To explore the effects of unilateral brain lesions, of oral reading with expression (RE) and comprehension (RC) on delayed recall of a story, as either UC or CC; and to validate the ability of UC and CC to discriminate the side of brain injury. Methods: Data were obtained from 200 right-handed volunteers, among whom 42 had left-hemisphere injury (LHI), 49 had right-hemisphere injury (RHI) and 109 were demographically-matched healthy participants (HP). Patients who were unable to read, understand or speak were excluded. Results: LHI individuals presented impairment of both UC and CC, in relation to the other two groups (non-LHI) with sensitivity and specificity above 70\%. LHI and RHI individuals were not significantly different in RE and RC, but they were both different from HP in all the assessments except CC, in which RHI individuals resembled HP. Despite this lack of abnormality in RHI individuals during CC, about half of this group showed impairment in UC. Additionally, whereas RE had a significant effect on UC, the moral of the story (RC) had a significant effect on both UC and CC. Conclusions: The left hemisphere was dominant for this memory task involving implicit processing.
\end{abstract}

Keywords: Cognitive Dysfunction; Diagnosis; Narration; Neuropsychological Tests; Validation Study.

\section{RESUMEN}

Antecedentes: No existen estudios en adultos con lesiones cerebrales unilaterales sobre la lectura de una historia, con comprensión y memoria incidental/implícita, midiendo sólo el recuerdo diferido. Se necesita validar la lateralidad cerebral en este tipo de recuerdo verbal que incluye: desempeño espontáneo (condición sin claves (CS) o libre) y desempeño inducido con preguntas sobre las unidades olvidadas (condición con claves (CC)). Objetivos: Explorar el efecto de las lesiones cerebrales unilaterales, la lectura expresiva (LE) y la comprensiva (LC), sobre el recuerdo diferido de una historia, sea CS o CC. Validar CS y CC en su capacidad para discriminar el lado de la lesión cerebral. Métodos: Los datos se obtuvieron de 200 voluntarios diestros, 42 con lesiones del hemisferio izquierdo (LHI), 49 con lesiones del hemisferio derecho (LHD), y 109 participantes sanos (PS), equiparados demográficamente. Se excluyeron los pacientes que no pudieron leer, entender o hablar. Resultados: LHI resultó perjudicado respecto de los otros dos grupos (no-LHI) en CS y CC, con una sensibilidad y especificidad superior al 70\%. LHI y LHD no se diferenciaron significativamente en LE ni LC, pero ambos fueron diferentes de los PS en todas las evaluaciones excepto CC, en donde LHD se asemejó a los PS. A pesar de esta ausencia de anomalía en LHD durante CC, aproximadamente la mitad de LHD mostró deterioro en CS. Además, mientras que LE tuvo un efecto significativo en CS, la moraleja de la historia (LC) tuvo un efecto significativo tanto en CS como en CC. Conclusiones: El hemisferio izquierdo fue dominante para esta tarea de memoria que involucró procesamiento implícito.

Palabras clave: Disfunción Cognitiva; Diagnóstico; Narración; Pruebas Neuropsicológicas; Estudio de Validación.

\section{INTRODUCTION}

The reading (or listening) skills involved in comprehending simple stories are highly practiced over a lifetime ${ }^{1}$. Longterm working memory (LTWM) is conceived as a subset of long-term memory that is directly retrievable in short-term working memory; it is restricted to well-practiced tasks and familiar knowledge domains ${ }^{1}$. LTWM is available not just to experts in their domain of expertise; for a simple story, everyone has the necessary expertise to comprehend and retrieve

${ }^{1}$ Consejo Nacional de Investigaciones Científicas y Técnicas de la Argentina (CONICET), Universidad Nacional de Córdoba, Instituto de Humanidades, Córdoba, Argentina

${ }^{2}$ Hospital Córdoba, Servicio de Neurología y Neurocirugía, Córdoba, Argentina.

NSV (iD) https://orcid.org/0000-0003-3545-0610

Correspondence: Nora Silvana Vigliecca; Email:nsvigliecca@gmail.com.

Conflict of interest: There is no conflict of interest to declare.

Support: This study was supported by funds from CONICET.

Received on October 20, 2020; Received in its final form on December 30, 2020; Accepted on January $26,2021$. 
relevant knowledge or personal experiences automatically, without special effort, and remember what has been read ${ }^{1}$.

With regard to visualization, perception of a story probably occurs without conscious awareness since automatic mental associations organize the sequence of events so that they line up with the story ${ }^{2}$. When reading a narrative, comprehension and retention of information benefit considerably from the use of situation models ${ }^{1,3,4}$. These models appear to depend upon interactions between the language system and complementary extra-linguistic cognitive processes, including attention, working memory, long-term memory and implicit activation of semantic associations as the story unfolds ${ }^{5}$. There are also contributions from emotional knowledge, visual imagery, empathy and abstraction ${ }^{5}$.

In functional studies, multiple regions have been reported to be involved in narrative processing. Nevertheless, since narrative-specificity in brain function may arise at a hemispheric rather than at a regional level ${ }^{4}$, there is a need for validity studies on the role of cerebral laterality of injury in story comprehension and recall, which have been poorly investigated at a hemispheric level. This need arises also in view of the contradictory results regarding laterality and narrative processing, not only from studies on patients with brain impairments ${ }^{3,6}$, and especially on those with temporal lobe epilepsy ${ }^{7-12}$, but also from functional or anatomical studies on healthy subjects ${ }^{4,5,13-23}$.

Bilateral involvement and the (theoretically-subtle) interactions among explicit, implicit, and working memory have been increasingly incorporated into new studies on narrative

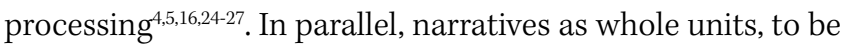
understood and/or remembered, have been more frequently examined in natural settings ${ }^{6-8,10-12,20,22}$. Other than this, they have generally been used as the reference context for interpreting experimental manipulations with the aim of assessing attention to selected story features ${ }^{14,16,18,23}$.

With regard to implicit memory, most studies have been carried out under experimental conditions, in order to try to exclude conscious awareness. However, it is difficult to transpose experimental conditions to more ecological settings, such as public hospitals. Even so, it seems evident that, in general, a healthy living human being, ought to be able to pay attention to what is relevant for survival without needing to be encouraged to do so. Correspondingly, and as a sample of that behavior, it is of interest to ascertain the extent to which adult readers have the ability to understand and memorize what is relevant in a story, without being instructed, particularly when they have been carefully instructed within the evaluation context.

A reading-telling story-test is used here to assess reading fluency and oral expression (RE), reading comprehension and abstraction (RC) and delayed recall of the story under two conditions: free or uncued condition (UC) and induced-throughquestion or cued condition (CC). During CC, participants are only asked about the forgotten units, mainly for the purpose of saving time during the assessment. Saving evaluation time is relevant in this type of investigation because the study samples are composed of patients with unilateral brain lesions, and they may easily become fatigued.

The story is administered as part of a larger battery of neuropsychological tests and participants are instructed that they should read the story in the same way as other reading items. Because the requirements to think about what is read or to remember what is read are intentionally avoided, the cognitive processes of comprehending and later recalling the story are spontaneously organized by the examinee ${ }^{28}$.

Narrative comprehension and memory are defined here as incidental or implicit because the story and its meaning are unintentionally learned while the participants are consciously engaged in fluent reading. Besides, fluent reading in itself is considered as a manifestation of implicit procedural memory in this sample of adult participants.

In this context, it would be desirable to know whether either $\mathrm{RE}$ or $\mathrm{RC}$ has an effect on delayed recall of the narrative, i.e. on the process of encoding and storing in memory the details of a story that the examinees are asked to recall several minutes (and several tasks) later, without the possibility of rehearsal.

Since there are no studies on adults with unilateral brain lesions about reading a story with incidental/implicit comprehension and memory, in which the latter is assessed only through delayed recall of UC and CC, the main objectives of the present study were the following: to explore the effects of unilateral brain lesions and of $\mathrm{RE}$ and $\mathrm{RC}$ on delayed recall of a story, as either UC or CC; to validate the ability of UC and $\mathrm{CC}$ to discriminate the side of brain injury; and to explore the effect of unilateral brain lesions on RE and RC.

\section{METHODS}

\section{Material}

The reading-telling story-test of the battery of Neuropsychological Tests Abbreviated and Adapted for Spanish Speakers ${ }^{29}$ (NTAASS) was studied (see Table 1-a). This test is used to assess RE, RC and (only) delayed recall under UC and $\mathrm{CC}$ conditions.

From a collection of tales and fables ${ }^{30}$, the original version of the story was selected and abbreviated to less than 130 words for NTAASS; accordingly, it was also adapted to be easily read and understood by children, by poorly educated people and, particularly, by patients with brain injuries. The narrative is not emotionally neutral (in terms of arousal) and uses simple language with factual descriptions of situations and events. The adapted version was divided into 25 subunits (from now on referred to as 'units' for recall) as shown in Table 1-a.

Although the story was administered as part of the NTAASS, in this study only RE, RC, UC and CC were analyzed. The story was the stimulus that triggered performance of the four tasks analyzed. This series of tasks began with RE and was immediately followed by RC. At the other end, UC and CC were successively administered after a delay interval of about 15 minutes, 
A) Story used as stimulus for the read-and-recall task

1) Text in Spanish abbreviated and adapted from the original version of the story ${ }^{30}$

El Huerfanito: Elisa /y Bernardo/ un matrimonio de granjeros/ que no tenían hijos/, decidieron ir a un orfanato/y adoptar uno/. La mujer/ quería una rubiecita de ojos azules/. Apenas llegaron, Elisa descubrió/ a la niña de sus sueños/ y se acercó a ella./ Un niñito rengo/y feo/ que había mirado con esperanza al matrimonio,/ se sintió inundado por la tristeza/ al ver que siempre elegían los niños más bellos./ Entonces el granjero advirtió a su mujer/ que ese niño los necesitaba más,/ y que la niñita con seguridad encontraría otros padres./ El huerfanito resultó ser un excelente hijo,/ además de bueno,/ trabajador/ e inteligente./ Pronto el hogar se lleno de felicidad./ Los granjeros sintieron que habían hecho lo correcto/.

2) English translation

The Little Orphan: Elisa/ and Bernardo/, a couple who were farmers/ who had no children/ decided to go to an orphanage/ to adopt a child/. The woman/ wanted a little girl with blonde hair and blue eyes/. On arrival, Elisa found/ the girl of her dreams/and approached her/. A one-legged/, ugly little boy/ who hoped to be chosen by the couple/felt very sad/ to see that people always choose the most beautiful children/. Then the farmer told his wife/ that this boy needed them more/, and that the little girl would surely find other parents/. The little orphan turned out to be an excellent son/, intelligent/, hardworking/, and good person/. Soon the home was filled with happiness/. The farmers felt that they had done the right thing/.

Note: The slashes indicate the 25 units to be recalled.

B) Intermediate Tests between the Reading Tasks and Delayed Recall Tasks ${ }^{29}$

1) Postural and motion sequence imitation (kinesthesia, allocentric left/right notion, rhythm, motor coordination and memory.

2) Copy of graph sequences.

3) Visual memory: face recognition.

4) Visual memory: retrieval of a complex figure.

5) Graphesthesia.

6) Recognition and naming of colors.

7) Stereognosis.

8) Finger recognition.

9) Non-verbal auditory agnosia.

10) Retrieval and/or recognition of a proper noun (delayed recall).

C) Note prior to the procedure. Before the assessment, the examiners were instructed to memorize the whole story, using word-forword recall as well as prosodic features, and then memorize the units (indicated by the slashes shown above (part (a)), as pauses in the narration. In this way, they no longer needed to read the text in any step of the investigation in order to match each examinee's response with the equivalent target of the text.

D) Note about use of a recorder. This battery was developed with the intention of using just papers, pencils and a handful of commonly used objects, to simplify administration (and scoring) in public hospitals at any moment. To reduce resources and time, we did not use a recorder. In any case, all participants underwent the same procedure.

E) RC. Moral-of-the-story guidelines: attention should be paid to matters that go beyond appearance, external beauty or prejudices (which includes the notions of solidarity and empathy, as well as the conviction that kindness is contagious), to lead to a rewarding result: the happiness and wellbeing of the orphan and his family. (Note for the examiners: generally, the answers are given in the form of idioms and proverbs). Example of a response with a score of 3: "The essential is invisible to the eyes... The essential is love... What you sow today, you will reap tomorrow. So, sooner or later, If you offer kindness, you will receive kindness".

F) Complementary reliability information

A group of $43 \mathrm{HP}$ was re-evaluated for inter-rater reliability. In this sample of $42.23 \pm 17.78$ years of age, 21 participants were females and 22 males; 19 had first-level education, 14 second-level, and 10 third-level. Two trained examiners acting independently evaluated the RE, RC, UC and CC performances of the same examinee. Specifically, the second rater interpreted the first rater's written records of the administration protocol, in which the first rater's comments about the examinee's performance were available but the final score was hidden. This was possible because verbatim responses were recorded for RC and UC, and multiple observations were feasible during RE and CC. Inter-rater reliability was analyzed by means of the intra-class correlation coefficient (ICC); differences between the two raters were analyzed using Student's t test for dependent samples (degrees of freedom (df) $=42$ ). Reliability was $>0.70$, without significant differences between the two raters for these four measurements (statistical data: RE: $t=$ $0.44, p=0.66$, Rater 1: $2.77 \pm 0.48$, Rater 2: $2.74 \pm 0.54, I C C=0.74 ;$ RC: $t=0.37, p=0.71$, Rater 1: $2.60 \pm 0.58$, Rater $2: 2.58 \pm 0.59, I C C=$ 0.72; UC: $t=-0.82, p=0.41$, Rater 1:38.91 \pm 13.76 , Rater 2:39.42 \pm 13.74, ICC $=0.95$; CC: $t=0.15, p=0.88$, Rater 1:3.19 \pm 1.78 , Rater 2: $3.16 \pm 1.66, I C C=0.82)$.

Note: This study was conducted in collaboration with Silvia Cristina Molina; additionally, as this was a one-shot test, test-retest reliability was not performed.

G) Additional data for discussion

The correlation between RE and RC is particularly interesting in this design because of the increase in the measurement error that results from using an incidental task of comprehension, i.e. performance in this task is highly dependent on the participants' own motivations and abilities to focus on the content of the story. Emotional working memory and attention status during the acquisition phase are essential for good performance ${ }^{9}$. Correspondingly, in a previous study relating to these processes, the present task of storytelling turned out to be useful for detecting patients with tangential speech, whose performance was dependent on attentional mechanisms, but not on the laterality of brain injury ${ }^{28}$. 
High-level cognitive tasks typically associated with working memory processes, such as reading, can be performed independently of conscious awareness ${ }^{24,25,27}$. From the current design, both implicit procedural memory processes involved in RE with RC and unexpected delayed recall were probably performed in this way. Furthermore, working-memory span correlates with the ability to remember information that was poorly integrated into the story as a whole ${ }^{26}$. In the present research, this ability may have enabled the (distracted) participants to grasp some gist keywords that were still reverberating in the working memory circuits, from RE, to generate an inference during RC.

Curiously, the observed pattern of laterality in the free or spontaneous recall of the story (UC), was similar to that found in the free or spontaneous recall of a confrontation naming task, in a previous study ${ }^{31}$. This finding may be easier to understand under the following assumption: a word, sentence, and story are all language structural and semantic units, organized and encoded in different episodic contexts. Within the current ecological context, by treating the narrative as a whole unit, it is probable that encoding and retrieval of narrative information has been done as a unit. Moreover, within this particular context of incidental memory, the two approaches (i.e. story and name recall) are likely to be more similar because the items to be recalled are tested without forewarning. Maybe for these reasons, the laterality for UC was similar to that of uncued picture naming, even if in the present task of story recall non-verbal stimuli were absent (see 'visual imagery' in the Introduction) ${ }^{5}$. Lastly, it is possible that in the current and previous study ${ }^{31}$, apart from the serious impairment of LHI, the moderate impairment of RHI was probably due to the contribution of the right hemisphere to memory function in general, independently of the type of input.

LHI: patients with left hemisphere injury, RHI: patients with right hemisphere injury; HP: healthy participants; RC: oral reading comprehension; RE: oral reading with expression; UC: uncued condition in story delayed recall; CC: cued condition in story delayed recall.

during which other tests were administered (see these tests in a previous study ${ }^{29}$ and in Table 1-b).

\section{Participants}

Data were obtained from a sample of 200 Argentine righthanded volunteers, who were all native Spanish speakers.

Among these volunteers, control data were obtained from 109 healthy participants (HP), who were community-dwellers without any known neurological or psychiatric disease. The recruitment method is further described elsewhere ${ }^{31}$.

Clinical data were obtained from the remainder of these volunteers: 91 consecutive preoperative in-patients (who ultimately underwent surgery) with unilateral focal cerebral lesions of multiple types. The sample was recruited from the Neurological and Neurosurgery Service of Cordoba Hospital, which is a public hospital for adults. The lesions were confirmed by means of CT scan and/or MRI techniques, and also through complementary diagnostic studies. None of the patients was suffering from any other (previous or simultaneous) associated neurological disease. The tests were administered and scored blindly in relation to both neuroanatomical and clinical data. It needs to be noted that the inclusion and exclusion criteria described here are only relevant to the present stage of the NTAAS.

Patients were only included if they were able to reach this NTAAS stage, and if they were also alert and willing to complete the fourteen tests going from the reading task ( $\mathrm{RE}$ and $\mathrm{RC})$ to the delayed recall of the story (UC and $\mathrm{CC}$ ), including the intermediate tests (Table 1-b).

Patients were excluded if they were unable to understand the test instructions, or if they had illiteracy, aphasia, alexia, hemineglect, visual field defects or sensory or motor difficulties that might prevent them from reading the story, or from giving an answer in RC, UC or CC. It should be noted, regarding language expression, that the following patients were excluded: those with $\mathrm{RE}=0$ (see below); and those with a slight impairment of spontaneous speech ${ }^{32}$. Hence, apart from alexia, cases of impairment of understanding of the current instructions or slight impairment of the spontaneous speech involved in the present reading and memory tasks were taken as indicative of aphasia, because these types of measurements have been validated for this purpose ${ }^{32}$. In general, patients with acute aphasia are not willing to complete these tests. Therefore, they are usually not included.

The initial sample consisted of 96 patients among whom three patients with left-hemisphere injury (LHI) were excluded because they presented aphasia with alexia, with impairment of spontaneous speech, and/or had difficulty understanding the test instructions. One right-hemisphere injury (RHI) patient was excluded because of illiteracy; and another RHI patient was excluded due to hemianopia with hemineglect.

For inclusion in this study, all the participants (or their caregivers) signed an informed consent statement. This research was approved by the Research Ethics Committee of Cordoba Hospital and was carried out in accordance with the ethical standards established in the Declaration of Helsinki ${ }^{33}$.

HP were demographically matched with LHI and RHI participants. This sample was used to determine the following: (i) the effect of unilateral brain lesions (along with RE and RC) on UC and CC; (ii) the validity of UC and CC for discriminating, on the one hand, between non-LHI (RHI and HP) and LHI, and on the other hand, among LHI, RHI and HP; and (iii) the effect of unilateral brain lesions on RE and RC.

LHI and RHI individuals were compared regarding their clinical variables, which included disease duration, risk factors for cognitive impairment and brain lesion type and site.

\section{Procedure}

The story was shown on one page, in conjunction with a series of other reading tasks, which included the general title of the task ("Reading"), four numbers of increasing difficulty to read, three non-words of three syllables, the title of the story ("The Little Orphan") and the story itself. The task instruction 
was just "read" or, if necessary, "read aloud the whole page, starting from the title" (see Table 1-c). In view of the rest of the stimuli displayed during RE, which may have acted as a distractor for RC, the reader's skill in implicitly balancing RE and RC was additionally challenged. Furthermore, given that reading fluency involves prosody, and that prosody has been correlated with RC ( for example, see a previous study ${ }^{34}$ ), the relationship between RE and RC was independently analyzed through the present method.

Immediately after the participants finished reading, the reading page was taken away from them and they were asked whether they knew the story. RC was then administered, with the following question: What does this story mean? That is, what is the moral of the tale or what message is the author trying to convey?

If the participants did not understand the task, the instructions were repeated (only once) using different words, e.g.: What lesson is the author trying to teach?

Next, the participants were also asked if they have anything else to add. The responses (including any added information) were recorded verbatim.

Then, after the intermediate tests, UC was administered, with the following instructions: Do you remember the little orphan's tale? Tell me it again and try to use exactly the same words as they appeared in the text. Ifyou cannot do it exactly, tell me what you remember about it. Tell me slowly because I'm going to write what you tell me. It is like a dictation (see Table 1-d).

After the participants had given their responses, $\mathrm{CC}$ was administered without any instruction. Participants were simply asked about the first units that had not been spontaneously remembered. This consisted specifically of asking the corresponding unit question according to its order of appearance in the text, when approximately $50 \%$ of the information for that unit was not remembered.

Ordinal scales were used as a comparison parameter for assessing RE, RC, $\mathrm{UC}$ or $\mathrm{CC}$, according to the number of items for each measurement.

$\mathrm{RE}$ was scored from 0 to 3 according to the ability to read with fluency and oral expression; i.e. null: 0; poor: 1; fair: 2; or good: 3 , as follows:

$0=$ absence of reading in quantity (fluency) or quality (accuracy).

1 = severe impairment of reading in terms of quantity, or distortion in quality.

2 = slight impairment of reading in terms of quantity, or distortion in quality.

$3=$ correct or normal reading (in terms of both quantity and quality).

$\mathrm{RC}$, i.e. the moral of the story, was assessed by providing guidelines and examples (Table 1-e, and see also the original source of the stor $\mathrm{y}^{30}$ ). $\mathrm{RC}$ was scored from 0 to 3 according to the ability to understand the story meaning and infer the moral of the story (i.e. comprehension/abstraction was scored as null: 0; poor: 1; fair: 2; or good: 3), as follows:

$0=$ none of the answers were relevant.

$1=$ some of the answers were relevant.

$2=$ most of the answers were relevant.

$3=$ all of the answers were relevant.

During UC, which was announced, the learner's skill in implicitly balancing storing and forgetting during the process going from the reading task to the delayed recall of the story was assessed. Thus, the residual memory that persisted after passing throughout the intermediate tasks were compared in the three groups. During CC, which was also announced, questions relating to previous performance and the forgotten units were asked, e.g. "what were the spouses' names?", "what did they do for a living?", etc.

Although gist recall was used for scoring in $\mathrm{UC}$ and $\mathrm{CC}$, the possibility of recalling the exact words for a certain unit of information was not separately considered. Instead, it was incorporated into the score and rated as the maximum point on the scale. Thus, on a scale from 0 to 4 , recalling the exact words was scored as 4 . The same score was given to participants who recalled the exact words, except for a small number of function words, e.g. "Elisa in company with Bernardo". It should be noted that in cases of any doubt about the performance, the pertinent CC question was asked. Additionally, when examinees did not answer a certain question, examiners did not tell them what the correct answer was.

UC was scored based on the 25 units shown in Table 1-a. Each unit was scored from 0 to 4 according to recall accuracy, i.e. null: 0; poor: 1; fair: 2; good: 3; or perfect or near-perfect: 4 (range: 0-100), as follows, such that the participant:

$0=$ did not recall anything, or the distortion was so great that the main idea was lost.

$1=$ recalled a small portion of the information, or with important distortion.

$2=$ recalled about half of the information, with some distortions.

$3=$ recalled the gist or the key point, through use of different words like synonyms, simplifications or extensions, with minimum distortion.

$4=$ recalled the exact words, except maybe for a small number of function words.

$\mathrm{CC}$ was scored based on units that were not spontaneously remembered by the examinee during UC. Each CC unit was scored from 0 (through 0.5) to 1; i.e. null: 0; moderate: 0.5 ; or good: 1 (range: $0-25$ ), as follows, such that the participant:

$0=$ did not recall anything, or the distortion was so great that the main idea was lost.

$0.5=$ recalled about half of the information, or with distortions. 
$1=$ recalled the gist or the key point, through use of different words like synonyms, simplifications or extensions, with minimum distortion.

Handedness was assessed by asking: With which hand do you write? Is that the strongest and most skilled hand for all activities? Tell me what you do with your preferred hand.

These questions were used because they have been validated for this purpose ${ }^{35}$.

\section{Statistical analysis}

When HP were compared with LHI and RHI individuals, regarding demographic variables, the data were analyzed by means of ANOVA for years of age or by means of the chi-square test for education and gender. When LHI and RHI individuals were compared regarding their clinical variables, the data were analyzed by means of ANOVA for disease duration and risk factors or by means of the chi-square test for lesion type and site. The relationship between $\mathrm{RE}$ and $\mathrm{RC}$ was assessed through Spearman's rank coefficient and the differences among all the groups regarding RE and $\mathrm{RC}$, through the Kruskal-Wallis nonparametric ANOVA, using multiple pairwise comparisons ${ }^{36}$.

In order to explore the effects of unilateral brain lesions and of RE and RC on delayed recall of the story, the following analysis was carried out. The group composed of LHI, RHI and HP was used as the independent variable in an ANOVA that had UC as the dependent variable and $\mathrm{RE}$ with $\mathrm{RC}$ as covariates; the Bonferroni post-hoc test was used for pairwise comparisons. The same analysis was separately carried out for CC. To illustrate and compare the patterns of performances for both UC and $\mathrm{CC}$, these variables were analyzed as dependent variables by means of bivariate MANOVA with the group composed of LHI, RHI and HP as the independent variable and RE with RC as covariates; the Bonferroni post-hoc test was used for pairwise comparisons; additionally, since UC and CC have different units of measurement, the data were transformed into ranks.

Receiver operating characteristic (ROC) curve analysis was performed to determine the sensitivity and specificity of UC and CC for differentiating non-LHI from LHI individuals. The cutoff point that produced the most uniform frequency distribution between sensitivity and specificity was considered to be the most satisfactory. In order to select optimal cutoff points based on several criteria, ROC curve analysis was done by means of the "Statistica" computer software, using neural networks and a linear model ${ }^{36}$.

The validity of UC and CC for discriminating among LHI, RHI and HP was investigated by means of cross-tabulation and the chi-square test, using the selected cutoff points.

\section{RESULTS}

Table 2 shows the matched demographic data for the three study samples.
No significant differences were observed between the two groups of patients regarding their clinical variables: disease duration in months (mean $\pm \mathrm{SD}$ ): $\mathrm{LHI}=35.09 \pm 76.09$, RHI $=32.98 \pm 67.19(\mathrm{~F}(1,89)=0.02 ; \mathrm{p}=0.89)$; and risk factors for cognitive impairment (number): $\mathrm{LHI}=1.27 \pm 1.10, \mathrm{RHI}=1.17$ $\pm 1.11(F(1,89)=0.20 ; p=0.65)$. See Table 3 for site of lesion; see also Table 4 for lesion type, and for the difference between malignant tumors and the rest of the lesions, which totalized 25 for LHI individuals and 30 for RHI individuals (chi-square = 0.03 ; df: $1 ; p<0.87$ ). No significant differences were found (chisquare $=4.65$; df: $9 ; \mathrm{p}=0.86$ ) when lobe lesion sites were also compared (data not shown). Through taking into account only purely temporal lobe lesions, in line with the existing data in the literature on the subject, their frequencies were LHI $=11$ and $\mathrm{RHI}=9$, without significant differences $(\mathrm{p}=0.53)$. It should be noted that because it was not feasible to model lesion size here, in view of the numbers and heterogeneity of the lesions, this feature was not analyzed.

Considering the entire sample, none of the participants knew the story; the Spearman's rank correlation between RE and RC was 0.47 ( $p<0.0001)$. According to the Kruskal-Wallis test, there was a significant difference in RE among the three groups: $\mathrm{H}$ $(2 ; \mathrm{N}=200)=37.52$, with average ranks: LHI: 75.18, RHI: 80.30 and HP: 119.34; p 0.0001; and RC: $\mathrm{H}(2 ; \mathrm{N}=200)=44.12$, with average ranks: LHI: 64.58, RHI: 80.78 and HP: 123.21; $\mathrm{p}<0.0001$. There were significant pairwise comparisons between HP and either LHI or RHI ( $p<0.0005)$, and a non-significant difference between LHI and RHI (RE: $\mathrm{p}=1$; RC: $\mathrm{p}=0.55$ ).

The ANOVA with UC as dependent variable indicated that there were significant effects from both $\operatorname{RE}(\mathrm{F}(1,195)=7.72$; $\mathrm{p}<0.006)$ and $\mathrm{RC}(\mathrm{F}(1,195)=12.79 ; \mathrm{p}<0.0004)$. There was a main group effect: LHI: $18.78 \pm 13.45$, RHI: $28.27 \pm 14.95$ and HP: $39.73 \pm 12.54(\mathrm{~F}(2,195)=15.79 ; \mathrm{p}<0.0001)$; and there were significant pairwise comparisons: LHI vs. RHI: $\mathrm{p}<0.005$; and HP vs. either LHI or RHI: $p<0.0001$. (It should be noted that for this analysis and for all following ANOVAs that involved RE and RC as covariates, the covariate means were, respectively, 2.57 and 2.09). Additionally, in this analysis, the covariate effects on UC were $\beta=0.18, p<0.006$ for RE, and $\beta=0.24, p<0.0004$ for RC. Significant positive beta coefficients indicated that the covariates helped in performance enhancement.

The same ANOVA applied to $\mathrm{CC}$ as the dependent variable indicated that there was a non-significant effect for RE ( F (1, $195)=0.24 ; \mathrm{p}=0.6262)$ and a significant effect for $\mathrm{RC}(\mathrm{F}(1,195)$ $=6.33 ; \mathrm{p}=0.0127)$. There was a main group effect: LHI: $2.17 \pm$ 2.06, RHI: $3.88 \pm 2.00$ and HP: $3.89 \pm 2.21(\mathrm{~F}(2,195)=7.38 ; \mathrm{p}=$ $0.0008)$. There were significant pairwise comparisons of LHI with the other two groups: LHI vs. RHI: $\mathrm{p}<0.0005$; and LHI vs. HP: $\mathrm{p}<0.0001$; and there was a non-significant pairwise comparison between RHI and HP: $\mathrm{p}=1$. (It should be noted that if the number of questions asked was considered, the results did not change. Additionally, in this analysis, the covariate effects on $\mathrm{CC}$ were $\beta=0.04, \mathrm{p}=0.6262$ for RE and $\beta=0.20$, $p$ $=0.0127$ for $\mathrm{RC}$ ). 
Table 2. Demographic data for the three matched samples.

\begin{tabular}{|c|c|c|c|c|c|c|}
\hline \multirow{2}{*}{ Group } & \multirow{2}{*}{$\begin{array}{c}\text { Age } \\
(\text { mean } \pm S D)\end{array}$} & \multicolumn{3}{|c|}{ Education } & \multirow{2}{*}{$\begin{array}{c}\text { Gender } \\
\text { (number of women) }\end{array}$} & \multirow{2}{*}{$\mathrm{N}$} \\
\hline & & First level & Second level & Third level & & \\
\hline LHI & $43.17 \pm 14.82$ & 18 & 21 & 3 & 19 & 42 \\
\hline $\mathrm{RHI}$ & $41.78 \pm 13.28$ & 24 & 23 & 2 & 21 & 49 \\
\hline HP & $42.22 \pm 12.72$ & 49 & 48 & 12 & 49 & 109 \\
\hline \multirow[t]{3}{*}{ Total } & $42.31 \pm 13.26$ & 91 & 92 & 17 & 89 & 200 \\
\hline & $F(2,197)=0.13$ & & $c h i^{2}=2.47 ; d f: 4$ & & $c h i^{2}=0.72 ; \mathrm{df:} 2$ & \\
\hline & $p=0.88$ & & $p=0.65$ & & $p=0.96$ & \\
\hline
\end{tabular}

LHI: patients with left hemisphere injury; RHI: patients with right hemisphere injury; HP: healthy participants; F: statistics with degrees of freedom; chi²: chisquare statistics; df: degrees of freedom; p: p-value. The three levels of education from left to right are: $1^{\circ}$ ) elementary school, $2^{\circ}$ ) high school, $3^{\circ}$ ) college, university or higher education.

Table 3. Frequencies of focal brain lesions according to site in the group of patients.

\begin{tabular}{lcc}
\hline Lesion & \multicolumn{3}{c}{ Group } \\
\hline Site & LHI & RHI \\
A & 12 & 18 \\
P & 21 & 20 \\
AP & 5 & 7 \\
SC & 4 & 4 \\
Total & 42 & 49 \\
chi $^{2}=1.03 ; \mathrm{df:}: \mathrm{p}=0.79$ & & \\
\hline
\end{tabular}

LHI: patients with left hemisphere injury, RHI: patients with right hemisphere injury; A: anterior (frontal); P: posterior (temporal, parietal or occipital); AP: anteroposterior; SC: subcortical. chi²: chi-square statistics; df: degrees of freedom; $p$ : $p$-value.

The bivariate MANOVA that was carried out to compare the performance patterns for UC and CC as dependent variables is shown in Figure 1. This result, using LS means, coincided with what was the described for UC and CC considered separately: Wilks lambda $=0.77, \mathrm{~F}(4,388)=13.51, \mathrm{p}<0.0001$ (computed for covariates at their means); non-significant pairwise comparison: RHI vs. HP in CC ( $\mathrm{p}=1)$.

The optimal cutoff points for UC and CC are shown in Table 5 and the ROC curves for UC and CC are depicted in Figure 2. The sensitivity and specificity of UC and CC for differentiating non-LHI vs. LHI were above $70 \%$. More specifically, the sensitivity of UC for differentiating non-LHI vs. LHI was 76\% (32/42 for LHI) and the specificity was 73\% (116/158 for non-LHI). The sensitivity and specificity of CC for differentiating non-LHI vs. LHI was 71\% (i.e., 30/42 for LHI and 112/158 for non-LHI).

Considering UC and CC in the three groups (Table 5), the difference between LHI and HP was more evident, since most LHI scored $\leq$ the cutoff point, whereas most HP scored $>$ the cutoff point. However, considering only the frequency distribution of RHI, almost $50 \%$ and $74 \%$ of these patients scored > the cutoff point in UC and CC, respectively.

See complementary reliability information in Table 1-f.

It should be noted that all the univariate parametric results described in the present study were confirmed through nonparametric tests.
Table 4. Frequencies of focal brain lesions according to type in the group of patients.

\begin{tabular}{lcc}
\hline Lesion & \multicolumn{2}{c}{ Patient group } \\
\hline Type & LHI & RHI \\
\hline AVM & 5 & 3 \\
\hline BEN TU & 8 & 10 \\
\hline MAL TU & 17 & 19 \\
\hline ISQ STR & 2 & 3 \\
\hline HEM STR & 1 & 3 \\
\hline TBI & 4 & 2 \\
\hline ANEU & 2 & 3 \\
\hline MTS & 1 & 2 \\
\hline Others & 2 & 4 \\
\hline Total & 42 & 49 \\
\hline chi2 $=3.38 ; d f: 8 ; p=0.91$ & & \\
\hline
\end{tabular}

LHI: patients with left hemisphere injury; RHI: patients with right hemisphere injury; AVM: arteriovenous malformation; BEN TU: benign tumor; MAL TU: malignant tumor; ISQ STR: ischemic stroke; HEM STR: hemorrhagic stroke; TBI: traumatic brain injury; ANEU: aneurysm, MTS: mesial temporal sclerosis: Others: cyst or abscess ( $\mathrm{LHI}$ and RHI groups had one case of each type), subdural hematoma (two cases in RHI group). chi²: chi-square statistics; df: degrees of freedom; $p$ : $p$-value.

\section{DISCUSSION}

In the present study, predominantly left lateralization for narrative processing was found, as indicated by the impairment of implicit and delayed recall of a story that was observed among LHI individuals, compared with the other two groups, i.e. LHI was impaired in relation to non-LHI in both $\mathrm{UC}$ and $\mathrm{CC}$, with sensitivity and specificity above $70 \%$. The findings from the present study agree with those of studies that used the narrative as a whole unit, and verbal inputs and outputs ${ }^{6-8,10,12,20,22}$, except that the left-lateralization pattern extended beyond the temporal lobe in this study. Also in line with the present findings, concerning the input, activation that was more left-lateralized was previously observed in functional studies for reading than for listening comprehension ${ }^{13,21}$; and, concerning the output, a 
Table 5. Frequencies in the groups according to cutoff points of ROC curves on the story delayed recall under two conditions involving implicit processing.

\begin{tabular}{|c|c|c|c|c|c|}
\hline \multirow{3}{*}{ Group } & \multicolumn{2}{|c|}{ UC } & \multicolumn{2}{|c|}{$\mathrm{CC}$} & \multirow{3}{*}{ Total } \\
\hline & \multicolumn{2}{|c|}{ Cutoff point: 28} & \multicolumn{2}{|c|}{ Cutoff point: 3} & \\
\hline & $\leq$ & $>$ & $\leq$ & $>$ & \\
\hline LHI & $32(76 \%)$ & $10(24 \%)$ & $30(71 \%)$ & $12(29 \%)$ & 42 \\
\hline $\mathrm{RHI}$ & $25(51 \%)$ & $24(49 \%)$ & $13(26 \%)$ & $36(74 \%)$ & 49 \\
\hline HP & 17 (16\%) & $92(84 \%)$ & $33(30 \%)$ & 76 (70\%) & 109 \\
\hline \multirow[t]{2}{*}{ Total } & 74 & 126 & 76 & 124 & 200 \\
\hline & \multicolumn{2}{|c|}{ chi2 $=53.23 ; d f: 2 ; p<0.0001$} & \multicolumn{2}{|c|}{$c h i^{2}=25.42 ; d f: 2 ; p<0.0001$} & \\
\hline
\end{tabular}

LHI: patients with left hemisphere injury, RHI: patients with right hemisphere injury; HP: healthy participants; UC: uncued condition; CC: cued condition. Percentages of row counts are shown. chi²: chi-square statistics; df: degrees of freedom; $p$ : $p$-value.

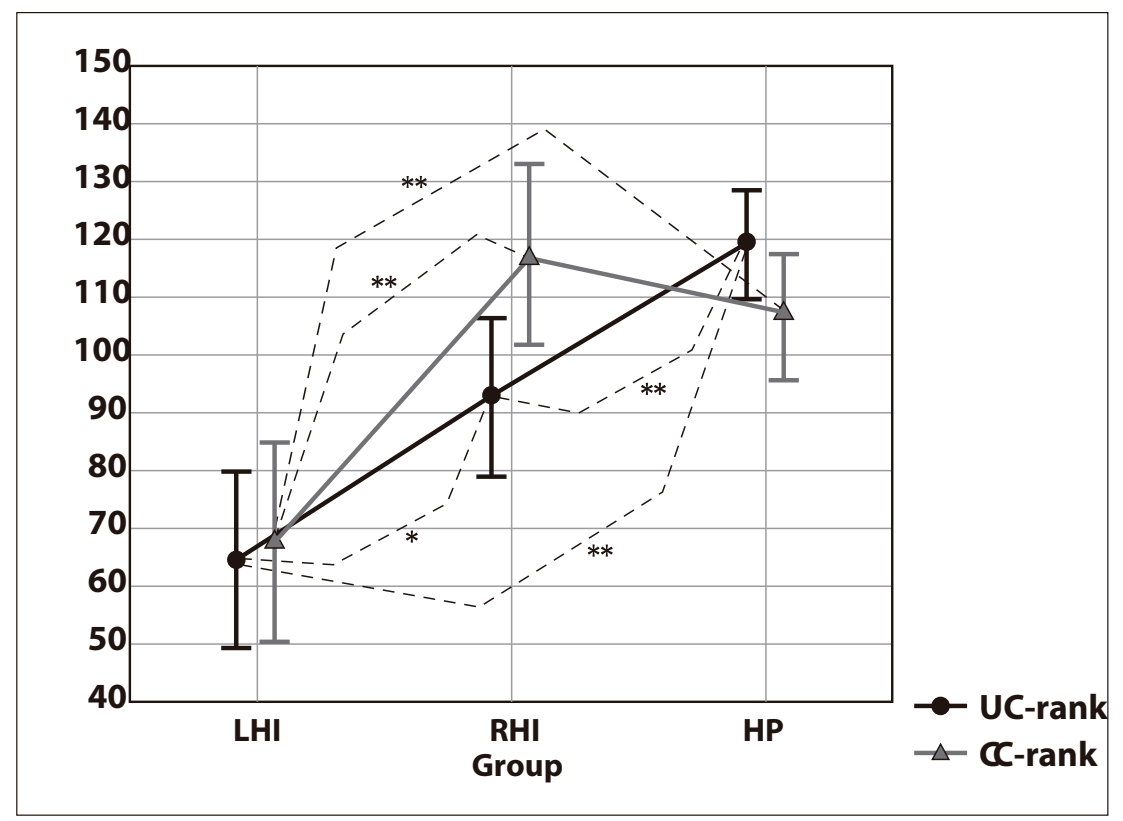

UC: uncued condition; CC: cued condition; LHI: patients with left hemisphere injury; RHI: patients with right hemisphere injury; HP: healthy participants. Vertical bars denote 0.95 confidence intervals. Significant pairwise comparisons: ${ }^{*} p<0.005,{ }^{* *} p<0.0005$.

Figure 1. Story recall test for UC and CC responses as a function of group.

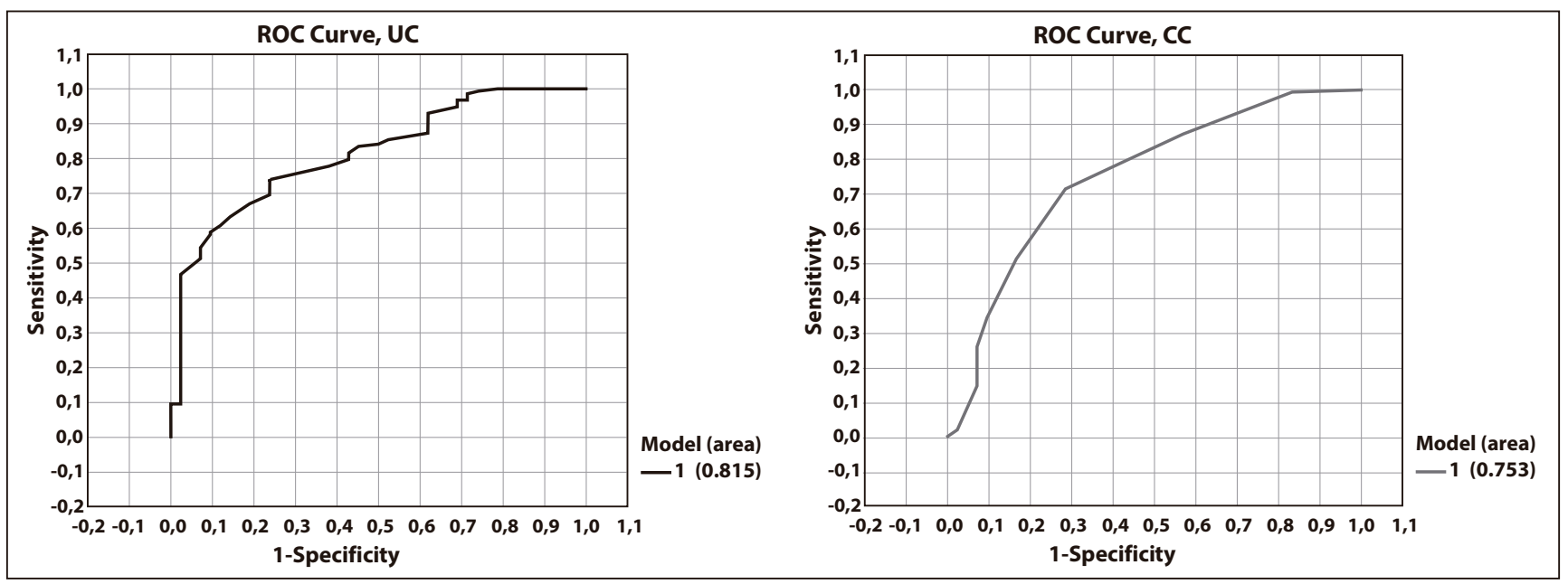

UC: uncued condition; CC: cued condition; LHI: patients with left hemisphere injury; RHI: patients with right hemisphere injury; HP: healthy participants.

Figure 2. Receiver operating characteristic (ROC) curves for UC and CC responses: Comparison between non- LHI (RHI and HP) and LHI for story recall test. 
network that is more left-lateralized was observed when the task involved language production aside from comprehension ( for review, see two previous studies ${ }^{28,31}$ ). Likewise, and considering the emotional content of the current narrative, a left-lateralized pattern was observed in patients with temporal lobe impairments who were evaluated regarding memory for stories and emotional material ${ }^{37,38}$.

Through exploring the effect of RE and RC on UC or CC, beyond laterality, the findings showed that whereas RE enhanced UC, the moral of the story (RC) enhanced both UC and CC.

Presentation of the narrative structure as an archetypal plot $^{39,40}$ may act as a priming factor ${ }^{40}$. Parsing narrative structure and decoding the serial order of narrative segments on a large scale probably involves a cortico-subcortical circuitry that includes the prefrontal cortex and higher-order cognitive behaviors ${ }^{5}$. From the present study, it can be proposed that the general structure of the story and the specific and sequential sections within the story (represented here by RE) acted as a sort of high-level syntax that implicitly enhanced UC. The lack of effect of $\mathrm{RE}$ on $\mathrm{CC}$ was probably due to the fragmentation of the story into the pieces of information asked about during CC. Moreover, because the participants had just performed UC, they surely realized that such questions referred to those items that they had not freely recalled. Therefore, they had to look for the missing information from the point at which they had collected the information in the first instance, but with greater depth of processing. That point was RC, rather than RE.

Rehearsal and memorization strategies during the process going from the reading task to the delayed recall of the story, through several intermediate tasks, were not possible under the present design. Therefore, the ability to remember the story in UC and CC, as residual memory, seems to have been due more to $\mathrm{RC}$ than to $\mathrm{RE}$, i.e. through making inferences about the meaning or moral of the story, which involves high-level cognitive ability. This seems to have been helpful not only for extending working memory, but also for enhancing encoding under the two conditions of implicit and delayed recall.

Additionally, the correlation between $\mathrm{RE}$ and $\mathrm{RC}$ was significant, thus probably indicating that the procedural memory involved in fluent reading was to a large degree linked to (procedural) reading comprehension.

Regarding RE and RC, and unlike the left-hemisphere dominance observed for the implicit or incidental learning of the story (see above), no differences were found in the present sample of patients without aphasia between LHI and RHI in $\mathrm{RE}$ and RC. However, these patient groups were both different from $\mathrm{HP}$ in all the assessments except $\mathrm{CC}$, in which $\mathrm{RHI}$ individuals resembled HP. The somewhat poor performance of HP in CC, compared with RHI, was probably caused by the good performance of HP in UC, i.e. by the lack of forgotten units in terms of gist recall. Alternatively, despite the lack of abnormality of the RHI individuals in CC, about half of these patients showed impairment in UC.

The increasing number of studies reporting bilateral involvement for narrative processing and the contradictory results regarding its laterality ${ }^{3-23}$ are consistent with impairment of RHI individuals in UC. In any case, LHI individuals were the most impaired group under any memory condition of this narrative task. See supplementary information in Table 1-g.

Study limitations: Considering that $\mathrm{RE}$ precedes $\mathrm{RC}$, it is likely that RE may have affected the subsequent measurement of $\mathrm{RC}$ rather than vice versa. Additionally, comparison of patients with different types of lesions may have increased the error. Although the present results were obtained despite such error, which was similarly distributed among LHI and RHI individuals, more evidence is needed in order to replicate these results in other samples or under other conditions. Likewise, because this was an exploratory study that dealt with verbal memory, the interference of linguistic parameters with memory also needs to be reviewed.

In conclusion, despite the multiple brain regions and bihemispheric engagement reported in previous studies on narrative processing, the language areas of the left hemisphere remain the common denominator underlying those investigations.

In line with classical studies on aphasia, the present validity study, which excluded aphasia, predominantly showed left lateralization for narrative processing, particularly for memory processing, i.e. the left hemisphere was dominant in this memory task of delayed story recall involving implicit processing.

\section{ACKNOWLEDGEMENTS}

Thanks to the neurosurgery team at Cordoba Hospital who provided neuroanatomical data and characterization of the lesion.

\section{REFERENCES}

1. Kintsch W, Patel VL, Ericsson KA. The role of long-term working memory in text comprehension. Psychologia. 1999 Dec;42(4):186-98.

2. Kawakami N, Yoshida F. Perceiving a story outside of conscious awareness: when we infer narrative attributes from subliminal sequential stimuli. Conscious Cogn. 2015 May;33:53-66. https://doi. org/10.1016/j.concog.2014.12.001

3. Ferstl EC, Walther K, Guthke T, von Cramon DY. Assessment of story comprehension deficits after brain damage. J Clin Exp Neuropsychol.

2005 Apr;27(3):367-84. https://doi.org/10.1080/13803390490515784

4. Yarkoni T, Speer NK, Zacks JM. Neural substrates of narrative comprehension and memory. Neuroimage. 2008 Jul 15;41(4):1408-25. https://doi.org/10.1016/j.neuroimage.2008.03.062

5. Xu J, Kemeny S, Park G, Frattali C, Braun A. Language in context: emergent features of word, sentence, and narrative comprehension. Neurolmage. 2005 Apr 15;25(3):1002-15. https://doi.org/10.1016/j. neuroimage.2004.12.013 
6. Formisano R, Schmidhuber-Eiler B, Saltuari L, Cigany E, Birbamer G, Gerstenbrand F. Neuropsychological outcome after traumatic temporal lobe damage. Acta Neurochir (Wien). 1991 Mar;109(1-2): 1-4. https://doi.org/10.1007/BF01405688

7. Djordjevic J, Smith ML, Sziklas V, Piper D, Pénicaud S, Jones-Gotman M. The Story Learning and Memory (SLAM) test: equivalence of three forms and sensitivity to left temporal lobe dysfunction. Epilepsy Behav. 2011 Mar 1;20(3):P518-23. https://doi.org/10.1016/j. yebeh.2011.01.002

8. Fuentes D, Malloy-Diniz LF, Gorenstein C, Christe B, Busatto GF. Learning and memory and its relationship with the lateralization of epileptic focus in subjects with temporal lobe epilepsy. Rev Psiquiatr Clín. 2014 Apr;41(1):1-4. https://doi.org/10.1590/010160830000041114

9. Machado V de V, Frank JE, Tomaz C. Emotional declarative memory assessment of patients with mesial temporal lobe epilepsy and patients submitted to mesial temporal lobectomy. Arq Neuropsiquiatr. 2010 Oct;68(5):737-43. https://doi.org/10.1590/ S0004-282X2010000500012

10. Moore PM, Baker GA. Validation of the Wechsler Memory Scale-Revised in asample of people with intractable temporal lobe epilepsy. Epilepsia. 1996 Dec;37(12):1215-20. https://doi. org/10.1111/j.1528-1157.1996.tb00556.x

11. Soble JR, Eichstaedt KE, Waseem H, Mattingly ML, Benbadis SR, Bozorg AM, et al. Clinical utility of the Wechsler Memory Scale-Fourth Edition (WMS-IV) in predicting laterality of temporal lobe epilepsy among surgical candidates. Epilepsy Behav. 2014 Dec 1;41:P232-7. https://doi.org/10.1016/j.yebeh.2014.10.014

12. Vannest J, Szaflarski JP, Privitera MD, Schefft BK, Holland SK. Medial temporal fMRI activation reflects memory lateralization and memory performance in patients with epilepsy. Epilepsy Behav. $2008 \mathrm{Apr}$ 1;12(3):P410-8. https://doi.org/10.1016/j.yebeh.2007.11.012

13. Buchweitz A, Mason RA, Tomitch LMB, Just MA. Brain activation for reading and listening comprehension: an $\mathrm{fMRI}$ study of modality effects and individual differences in language comprehension. Psychol Neurosci. 2009;2(2):111-23. https://doi.org/10.3922/j. psns.2009.2.003

14. Chow HM, Kaup B, Raabe M, Greenlee MW. Evidence of frontotemporal interactions for strategic inference processes during language comprehension. Neuroimage. 2008 Apr 1;40(2):940-54. https://doi.org/10.1016/j.neuroimage.2007.11.044

15. Fedorenko E, Behr MK, Kanwisher N. Functional specificity for high-level linguistic processing in the human brain. Proc Natl Acad Sci U S A. 2011 Sep 27;108(39):16428-33. https://doi.org/10.1073/ pnas.1112937108

16. Hasson U, Nusbaum HC, Small SL. Brain networks subserving the extraction of sentence information and its encoding to memory. Cereb Cortex. 2007 Dec;17(12):2899-913. https://doi.org/10.1093/ cercor/bhm016

17. Nichelli P, Grafman J, Pietrini P, Clark K, Lee KY, Miletich R. Where the brain appreciates the moral of a story. Neuroreport. 1995 Nov 27;6(17):2309-13. https://doi.org/10.1097/00001756-19951127000010

18. Powers C, Bencic R, Horton WS, Beeman M. Hemispheric inference priming during comprehension of conversations and narratives. Neuropsychologia. 2012 Sep;50(11):2577-83. https://doi. org/10.1016/j.neuropsychologia.2012.07.008

19. Rapp AM, Mutschler DE, Erb M. Where in the brain is nonliteral language? A coordinate-based meta-analysis of functional magnetic resonance imaging studies. Neuroimage. 2012 Oct 15;63(1):600-10. https://doi.org/10.1016/j.neuroimage.2012.06.022

20. Rice DM, Buchsbaum MS, Hardy D, Burgwald L. Focal left temporal slow EEG activity is related to a verbal recent memory deficit in a non-demented elderly population.J Gerontol. 1991 Jul;46(4):P144-51. https://doi.org/10.1093/geronj/46.4.P144
21. Spitsyna G, Warren JE, Scott SK, Turkheimer FE, Wise RJS. Converging language streams in the human temporal lobe.J Neurosci. 2006 Jul 12;26(28):7328-36. https://doi.org/10.1523/ JNEUROSCI.0559-06.2006

22. Trifilio E, Tanner JJ, Butterfield L, Mangal P, Maye JE, Marsiske M, et al. A tale of two stories: validity of an alternative story memory test in a sample of older adults. Clin Neuropsychol. 2020 Jan;34(1):158-73. https://doi.org/10.1080/13854046.2018.1538428

23. Vigneau M, Beaucousin V, Hervé P-Y, Jobard G, Petit L, Crivello F, et al. What is right-hemisphere contribution to phonological, lexicosemantic, and sentence processing? Insights from a meta-analysis. Neuroimage. 2011 Jan 1;54(1):577-93. https://doi.org/10.1016/j. neuroimage.2010.07.036

24. Dutta A, Shah K, Silvanto J, Soto D. Neural basis of non-conscious visual working memory. Neuroimage. 2014 May 1;91:336-43. https:// doi.org/10.1016/j.neuroimage.2014.01.016

25. Henke K. A model for memory systems based on processing modes rather than consciousness. Nat Rev Neurosci. $2010 \mathrm{Jul} ; 11$ (7):523-32. https://doi.org/10.1038/nrn2850

26. Jeffries E, Ralph MAL, Baddeley AD. Automatic and controlled processing in sentence recall: the role of long-term and working memory. J Memory Lang. 2004 Nov;51(4):623-43. https://doi. org/10.1016/j.jml.2004.07.005

27. Velichkovsky BB. Consciousness and working memory: current trends and research perspectives. Conscious Cogn. 2017 Oct;55:35-45. https://doi.org/10.1016/j.concog.2017.07.005

28. Vigliecca NS. Neurocognitive implications of tangential speech in patients with focal brain damage. In: D'Onofrio G, Sancarlo D, Greco A, editors. Gerontology. London: InTechOpen; 2018. p. 191-220.

29. Vigliecca NS. Neuropsychological tests abbreviated and adapted to Spanish speakers: review of previous findings and validity studies for the discrimination of patients with anterior vs. posterior lesions. Rev Neurol. 2004 Aug 1-15;39(3):205-12

30. Corella LG, Busquets C. El Huerfanito Cojo. In: Busquets C, Corella LJ. 55 cuentos y fábulas. Madrid: Susaeta Ediciones S.A.; 1978. p. 42-4.

31. Vigliecca NS, Voos JA. Remembering a name: neuropsychological validity studies and a computer proposal for detection of anomia. Dement Neuropsychol. 2019 Oct-Dec;13(4):450-62. https://doi. org/10.1590/1980-57642018dn13-040013

32. Vigliecca NS. Validity and features of spontaneous speech in acute aphasia as evaluated with the Brief Aphasia Evaluation: is fluent aphasia more severe than nonfluent aphasia? Codas. 2019 Mar 7;31(1):e20180048. https://doi.org/10.1590/2317$1782 / 20192018048$

33. World Medical Association. World Medical Association Declaration of Helsinki: ethical principles for medical research involving human subjects. JAMA. 2013 Nov 27;310(20):2191-4. https://doi.org/10.1001/ jama.2013.281053

34. Kocaarslan M. The effects of reading rate, accuracy and prosody on second grade students' oral retelling. Acta Psychol (Amst). 2019 Jun;197:86-93. https://doi.org/10.1016/j.actpsy.2019.05.005

35. Trejo S. Lateralidad: cuestionario para la medición de la preferencia manual [Bachelor's thesis]. [Santiago del Estero]: Universidad Católica de Santiago del Estero; 1993.

36. StatSoft, Inc, Manual. STATISTICA: Data analysis software system. Version 7. Tulsa (OK): StatSoft; 2004.

37. Frank JE, Tomaz C. Lateralized impairment of the emotional enhancement of verbal memory in patients with amygdalahippocampus lesion. Brain Cogn. 2003 Jul;52(2):223-30. https://doi. org/10.1016/S0278-2626(03)00075-7

38. Múnera CP, Lomlomdjian C, Terpiluk V, Medel N, Solís P, Kochen S. Memory for emotional material in temporal lobe epilepsy. Epilepsy Behav. 2015 Nov 1;52(Pt A):P57-61. https://doi.org/10.1016/j. yebeh.2015.08.009 
39. Bolognani SAP, Miranda MC, Martins M, Rzezak P, Bueno OFA, de Camargo CHP, et al. Development of alternative versions of the Logical Memory subtest of the WMS-R for use in Brazil. Dement Neuropsychol. 2015 Apr-Jun;9(2):136-48. https://doi. org/10.1590/1980-57642015DN92000008
40. Cannizzaro MS, Dumas J, Prelock P, Newhouse P. Organizational structure reduces processing load in the prefrontal cortex during discourse processing of written text: implications for high-level reading issues after TBI. Perspect Neurophysiol Neurogenic Speech Lang Disord. 2012 Aug 1;22(2):67-78. https://doi.org/10.1044/ nnsld22.2.67 